\title{
PENGGUNAAN KARET NITRIL UNTUK PEMBUATAN KOMPON OIL SEAL
}

\author{
Siti Rochani ${ }^{1)}$ dan Christiana Maria $\mathrm{HP}^{1)}$.
}

\section{INTISARI}

Penelitian bertujuan untuk mendapatkan formulasi kompon oil seal yang optimum dengan menggunakan karet nitril. Dalam penelitian ini dibuat rancangan percobaan dengan 2 variasi yaitu perbandingan karet nitril / karet alam 70/20;75/15;80/10 dan jumlah bahan pengisi carbon black $45 \mathrm{phr}, 50 \mathrm{phr}$ dan $55 \mathrm{phr}$. Kompon dibuat dalam mesin two roll mill, kemudian divulkanisasi pada suhu $150^{\circ} \mathrm{C}$, tekanan $150 \mathrm{~kg} / \mathrm{cm}^{2}$ dan waktu sesuai dengan yang ditunjukkan oleh curometer. Dari 9 formulasi yang diteliti diperoleh formulasi kompon oil seal terbaik dan memenuhi persyaratan JIS. B.2402-76, terdiri atas karet nitril $70 \mathrm{phr}$, karet alam 20 phr, karet SBR 10 phr, carbon black 55 phr, DOP 15 phr, coumaron resin 5 phr, asam stearat $1 \mathrm{phr}$, zink oksida $5 \mathrm{phr}$, vulkanox HS 2 phr, paraffin wax $0,8 \mathrm{phr}$, minyak aromatik $6 \mathrm{phr}$, CBS 1,2 phr, TMT 0,1 phr Neoblend 2 phr dan sulfur 1,5 phr; dengan sifat fisis kekerasan 61,7 shore $A$, tegangan putus $12,01 \mathrm{~N} / \mathrm{mm}^{2}$, perpanjangan putus $383,8 \%$, pampat tetap $45,62 \%$, perubahan setelah perendaman dalam oli SAE $50 \mathrm{~W}, 100^{\circ} \mathrm{C}, 72 \mathrm{jam}$ : perubahan kekerasan $4,32 \%$; perubahan tegangan putus $16,35 \%$; perubahan perpanjangan putus $17,13 \%$; dan perubahan volume $1,38 \%$.

\begin{abstract}
The objective of the research was to find the optimum oil seal compound formula, which it was made from nitril rubber. This research was designed using two variable, namely nitrile rubber / natural rubber $(70 / 20 ; 75 / 15 ; 80 / 10)$ and the amount of carbon black (45 phr, $50 \mathrm{phr}, 55 \mathrm{phr}$ ). Compound was made in a two roll mill machine, and then vulcanized at temperature $150^{\circ} \mathrm{C}$, pressure of $150 \mathrm{~kg} / \mathrm{cm}^{2}$ and curing time as indicated by curometer. The best formulation among 9 formulations based on the requirments of JIS.B. 2402-76 was consist of nitril rubber $70 \mathrm{phr}$, natural rubber $20 \mathrm{phr}$, stirene butadiene rubber $10 \mathrm{phr}$, carbon black $55 \mathrm{phr}$, DOP $15 \mathrm{phr}$, coumaron resin $5 \mathrm{phr}$ stearic acid $1 \mathrm{phr}$, zink oxide $5 \mathrm{phr}$, vulkanox HS $2 \mathrm{phr}$, paraffin wax $0,8 \mathrm{phr}$, aromatik oil $6 \mathrm{phr}$, CBS 1,2 phr, TMT 0,1 phr, Neoblend 2 phr and sulfur 1,5 phr; with the physical properties were hardness 61,7 shore A, tensile strength $12,01 \mathrm{~N} / \mathrm{mm}^{2}$, elongation at break $383,8 \%$, compression set (constant deflection) 45,62\%, and the change of properties after immersion in $\mathrm{SAE} 50 \mathrm{~W}$ oil $\left(100^{\circ} \mathrm{C}, 72\right.$ hours) were : change of hardness $4,32 \%$; change of tensile strength $16,35 \%$; change of elongation at break $17,13 \%$; and change of volume $1,38 \%$.
\end{abstract}

1) Balai Besar Penelitian dan Pengembangan Industri Barang Kulit, Karet dan Plastik, Yogyakarta. 


\section{PENDAHULUAN}

Perkembangan industri otomotif mengalami peningkatan yang sangat pesat sejalan dengan kebijaksanaan mengenai diproduksinya mobil nasional di Indonesia. Perkembangan ini harus didukung dengan tersedianya komponen yang memadai baik dalam segi jumlah maupun kualitasnya.

Penggunaan komponen karet pada mobil penumpang mencapai 3\% sedangkan pada mobil truk mencapai $15 \%$. Diantara komponen karet untuk kendaraan bermotor, komponen yang mempunyai fungsi cukup penting adalah oil seal. Dari segi kegunaannya oil seal haruslah mempunyai sifat yang tahan panas, minyak, bahan kimia dan juga tahan tekanan tinggi.

Oil seal dibuat dengan formulasi karet nitril, SBR, RSS, bahan aditif dan bahan vulkanisasi. Karet nitril mulai dibuat pada tahun 1930, namun baru diproduksi secara komersial di Jerman pada tahun 1937 dengan merk dagang Buna N. Pada tahun 1970, telah diproduksi Buna N dengan \pm 200 grade oleh 17 produser, dan pada akhir tahun 1970 produksi dunia telah mencapai 200.000 ton per tahun. Kandungan akrilonitril pada karet nitril komersial bervariasi antara $25-50 \%$ dan yang biasa dijual di pasaran kandungan akrilonitrilnya $34 \%$ (Brydson JA, 1982). Struktur formula dari NBR adalah sebagai berikut :

$$
-\mid-\mathrm{CH}_{2}-\mathrm{CH}=\mathrm{CH}-\mathrm{CH}_{2}-\mathrm{CH}_{2}-\mathrm{CH}_{\mathrm{C}}^{\mathrm{C}} \equiv \mathrm{N}
$$

Butadiene

\section{Akrilonitrile}

Beberapa parameter yang memegang peranan penting didalam memproduksi NBR adalah kandungan akrilonitril (berpengaruh pada ketahanan terhadap minyak dan oli), temperatur polimerisasi, bahan pemodifikasi, penstabil, penambahan pelunak dan pencampuran dengan PVC (Hoffman 1989). Karet yang tidak mengandung monomer hidrokarbon sangat bagus ketahanannya terhadap minyak hidrokarbon dan minyak petroleum. Dengan bertambahnya kandungan akrilonitril didalam karet nitril akan menaikkan kompabilitas antara karet nitril dan plastik jenis PVC, sedikit menaikkan tegangan putus, kekerasan, ketahanan kikis serta mempunyai sifat yang lebih mudah diproses. Karet nitril bisa divulkanisasi dengan sulfur dan juga peroksida. Vulkanisat yang dihasilkan biasanya digunakan untuk membuat selang minyak dan seal (Maurice Morton, 1987).

Ketahanan terhadap minyak dari vulkanisat karet nitril dipengaruhi oleh dua faktor pokok yakni kandungan akrilonitril dalam kopolimer dan sifat kimia minyak / bahan bakar. Faktor lain yang mempengaruhi yaitu jenis bahan pelunak, pigmen, proses vulkanisasi/tingkat crosslinking, temperatur polimerisasi serta homogenitas polimer. Karet nitril mempunyai kompatibilitas yang kurang baik dengan karet alam, namun dengan adanya karet stiren butadien (SBR), karet alam bisa bercampur dengan baik dan merata (Maurice Morton 1987).

Untuk membuat barang jadi karet, karet nitril perlu divulkanisasi dengan tambahan beberapa jenis bahan kimia dengan tujuan untuk memperoleh barang karet yang mempunyai sifat yang dikehendaki dan memungkinkan kompon karet tervulkanisasi serta memudahkan pengerjaan pada pengolahan barang karet. Viskositas dan kemampuan proses dari NBR dapat diatur dengan penambahan bahan pelunak. Selain dua hal tersebut bahan pelunak juga mempengaruhi elastisitas dan ketahanan terhadap pengembangan (swelling). Jenis bahan pelunak yang biasa dipakai pada karet alam dan SBR seperti minyak parafin atau naphtenic mempunyai kompatibilitas yang sangat kecil dengan NBR karena adanya perbedaan polaritas. 
Bahan pelunak dari jenis ether dan ester dengan penggunaan sampai dengan 30 phr sangat

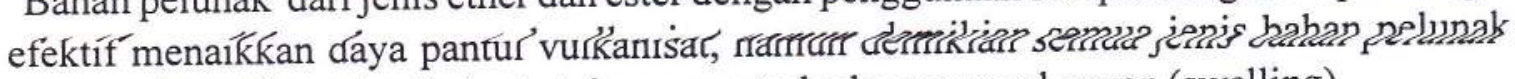
menurunkan sifat mekanik dan ketahanannya terhadap pengembangan (swelling).

Vulkanisat karet nitril yang merupakan jenis karet polar yang mempunyai ketahanan bagus, jika dicelupkan kedalam media yang non polar atau sedikit polar seperti gasolin, lemak, minyak mineral, serta minyak hewan dan tumbuhan. Ketahanan swelling tersebut sangat tergantung dari jenis NBR, bahan pembantu, jumlah bahan pengisi, type dan jumlah bahan pelunak serta derajad vulkanisasi. Untuk membuat vulkanisat NBR yang harus selalu diingat adalah jenis minyak apa yang akan kontak dengan vulkanisat tersebut. Jika vulkanisat tersebut kontak dengan minyak yang mengandung aditif sulfur dan nitrogen maka dipergunakan Tetra methyl thiuram disulfide (TMTD) kurang dari 2 phr untuk mengurangi pembentukan Ziak dimethyl dithio carbamat (ZDMC) (Hofman 1989).

\section{BAHAN DAN METODA PENELITIAN}

\section{Bahan penelitian}

Bahan penelitian terdiri atas bahan baku karet dan bahan kimia pembantu. Bahan baku karet yang dipergurakan adalah karet nitril, karet stiren butadien dan karet alam (RSS I); sedangkan bahan kimia pembantu terdiri atas bahan pengisi carbon black, bahan pelunak dioktil phtalat (DOP), minyak aromatik dan coumaron resin, penggiat asam stearat dan zink oksida $(\mathrm{ZnO})$, anti oksidan vulkanok HS, akselerator CBS dan TMT, bahan pembantu mastikasi neoblend, parafin wax, serta pemvulkanisasi sulfur. Bahan kimia pengujian dipergunakan oli SAE 50W.

\section{Peralatan}

Peralatan yang dipergunakan dalam penelitian terdiri atas : timbangan analitis, two roll mil, curometer, hidrolik press, cetakan slab, thermometer, alat uji tegangan putus dan perpanjangan putus, alat uji kekerasan (Shore A durometer), alat uji pampat tetap, dan alat uji pengusangan.

\section{Metoda penelitian}

\section{Formulasi kompon}

Dalam penelitian ini dibuat rancangan percobaan dengan 2 variasi yaitu perbandingan karet nitril / karet alam 70/20; 75/15; 80/10; dan jumlah carbon black 45 phr, 50 phr dan $55 \mathrm{phr}$; sehingga diperoleh 9 (sembilan) formulasi kompon seperti pada tabel 1 . 
Tabel 1: Formulasi kompon oil seal

\begin{tabular}{|l|l|c|c|c|c|c|c|c|c|c|}
\hline & & \multicolumn{10}{|c|}{ Formula } \\
\cline { 3 - 10 } No. & Bahan & D1 & D2 & D3 & D4 & D5 & D6 & D7 & D8 & D9 \\
\hline 1. & Karet nitril & 70 & 75 & 80 & 70 & 75 & 80 & 70 & 75 & 80 \\
2. & Karet SBR & 10 & 10 & 10 & 10 & 10 & 10 & 10 & 10 & 10 \\
3. & Karet alam & 20 & 15 & 10 & 20 & 15 & 10 & 20 & 15 & 10 \\
4. & Carbon black & 45 & 45 & 45 & 50 & 50 & 50 & 55 & 55 & 55 \\
5. & DOP & 15 & 15 & 15 & 15 & 15 & 15 & 15 & 15 & 15 \\
6. & Coumaron resin & 5 & 5 & 5 & 5 & 5 & 5 & 5 & 5 & 5 \\
7. & Asam stearat & 1 & 1 & 1 & 1 & 1 & 1 & 1 & 1 & 1 \\
8. & Zink oksida & 5 & 5 & 5 & 5 & 5 & 5 & 5 & 5 & 5 \\
9. & Vulkanox HS & 2 & 2 & 2 & 2 & 2 & 2 & 2 & 2 & 2 \\
10. & Paraffin wax & 0.8 & 0.8 & 0.8 & 0.8 & 0.8 & 0.8 & 0.8 & 0.8 & 0.8 \\
11. & Aromatik oil & 6 & 6 & 6 & 6 & 6 & 6 & 6 & 6 & 6 \\
12. & CBS & 1.2 & 1.2 & 1.2 & 1.2 & 1.2 & 1.2 & 1.2 & 1.2 & 1.2 \\
13. & TMT & 0.1 & 0.1 & 0.1 & 0.1 & 0.1 & 0.1 & 0.1 & 0.1 & 0.1 \\
14. & Neoblend & 2 & 2 & 2 & 2 & 2 & 2 & 2 & 2 & 2 \\
15. & Sulfur & 1.5 & 1.5 & 1.5 & 1.5 & 1.5 & 1.5 & 1.5 & 1.5 & 1.5 \\
\hline
\end{tabular}

2. Proses pembuatan kompon

Semua bahan ditimbang sesuai formulasi yang ditentukan. Bahan-bahan tersebut dikompon dengan mesin two roll mill. Mula-mula karet nitril, SBR dan RSS dimastikasi sampai plastis dengan ditambahkan parafin wax dan neoblend untuk memudahkan proses mastikasi Selanjutnya tambahkan berturut-turut coumaron resin, asam stearat, $\mathrm{ZnO}$, carbon black, DOP, minyak aromatik, vulkanox HS, CBS, dan TMT. Setelah semua bahan tersebut tercampur homogen, terakhir ditambahkan sulfur kemudian digiling lagi sampai betul-betul homogen. Kompon yang dihasilkan dikondisikan dalam ruangan dengan suhu $(23 \pm 2)^{\circ} \mathrm{C}$ dan kelembaban relatif $(65 \pm 5) \%$ selama 24 jam.

3. Pembuatan slab

Sebelum dilakukan pembuatan slab, kompon di test terlebih dahulu menggunakan curometer untuk mengetahui waktu vulkanisasi optimum. Kompon divulkanisasi dan dicetak menjadi bentuk slab dengan menggunakan press hidrolik pada suhu $150^{\circ} \mathrm{C}$, tekanan $150 \mathrm{~kg} / \mathrm{cm}^{2}$ dan waktu disesuaikan dengan waktu vulkanisasi optimum.

4. Pengujian

Pengujian dilakukan sesuai dengan JIS. B 2402 - 1976, Oil Seal yang meliputi : kekerasan, tegangan putus, perpanjangan putus, pampat tetap dan ketahanan terhadap minyak dengan mengukur perubahan kekerasan, perubahan tegangan putus, perubahan perpanjangan putus dan perubahan volume setelah perendaman dalam minyak SAE $50 \mathrm{~W}$.

5. Analisa data

Data hasil penelitian diolah secara statistik menggunakan rancangan faktorial, kemudian beda nyata antar variasi dihitung dengan Uji Duncan. 


\section{HASIL DAN PEMBAHASAN}

\section{Hasil Penelitian}

Hasil penelitian disajikan dalam tabel 2.

Tabel 2 : Hasil uji rata-rata kompon oil seal.

\begin{tabular}{|l|c|c|c|c|c|c|c|c|c|}
\hline \multirow{2}{*}{ Jenis Uji } & \multicolumn{9}{|c|}{ Formula } \\
\cline { 2 - 9 } & D1 & D2 & D3 & D4 & D5 & D6 & D7 & D8 & D9 \\
\hline Kekerasan, Shore A & 50.0 & 55.0 & 54.0 & 57.3 & 58.0 & 62.0 & 61.7 & 61.0 & 61.3 \\
Tegangan putus, N/mm ${ }^{2}$ & 12.70 & 12.13 & 11.08 & 10.67 & 12.98 & 14.32 & 12.01 & 10.34 & 12.02 \\
Perpanjangan putus, \% & 700.0 & 500.0 & 575.0 & 411.7 & 433.3 & 441.7 & 383.3 & 416.6 & 400.0 \\
Pampat tetap, \% & 70.41 & 45.14 & 63.92 & 81.45 & 78.16 & 87.26 & 45.62 & 43.16 & 78.96 \\
Ketahanan terhadap minyak pelumas & & & & & & & & & \\
Perubahan kekerasan, \% & 26.67 & 4.87 & 7.40 & 2.91 & 12.06 & 9.14 & 4.32 & 3.81 & 8.66 \\
Perubahan tegangan putus, \% & 27.80 & 7.61 & 17.15 & 10.22 & 10.27 & 8.73 & 16.35 & 6.56 & 28.03 \\
Perubahan perpanjangan & 53.57 & 31.66 & 52.46 & 25.29 & 23.31 & 28.67 & 17.13 & 36.57 & 16.66 \\
putus,\% & & & & & & & & & \\
Perubahan volume & 8.41 & 3.71 & 3.36 & 2.89 & 1.35 & 3.69 & 1.38 & 1.49 & 5.26 \\
\hline
\end{tabular}

Pembahasan

\section{Kekerasan}

Variasi perbandingan karet nitril dan karet alam, menunjukkan bahwa ada beda nyata antar variasi pada $\mathrm{p} \leq 0,05$. Makin banyak karet alam yang ditambahkan, ternyata kekerasannya makin turun. Kekerasan yang tertinggi adalah pada perbandingan karet nitril/karet alam 80/10, kemudian kompon dengan karet nitril / karet alam 75/15 dan yang terendah adalah kompon dengan karet nitril / karet alam 70/20. Hal ini kemungkinan disebabkan karena karet alam terbentuk dari rangkaian hidrokarbon yang tidak jenuh yang merupakan gugus reaktif, pada waktu proses vulkanisasi dengan sulfur. Oleh karena itu makin besar jumlah karet alam, kemampuan proses menjadi lebih baik dengan kekerasan cenderung turun. Untuk variasi carbon black ternyata juga menunjukkan beda nyata pada $\mathrm{p} \leq 0,05$. Kekerasan tertinggi adalah pada penambahan carbon black yang terbanyak yaitu 55 phr dan makin kecil jumlah carbon black yang ditambahkan kekerasannya cenderung turun. Hal ini disebabkan karena carbon black merupakan bahan pengisi yang bersifat menguatkan (reinforced) sehingga makin banyak carbon black yang ditambahkan kedalam karet, kekerasannya akan makin meningkat.

Menurut Hofman (1989), karet nitril bila ditambahkan filler yang bersifat reinforce seperti carbon black akan didapat sifat mekanik yang bagus, dan kekerasannya bisa dibuat dengan spektrum yang luas yakni dari kekerasan 20 shore A sampai dengan sekeras ebonit.

\section{Tegangan putus dan perpanjangan putus}

Berdasarkan hasil perhitungan statistik untuk tegangan putus terlihat pada penambahan carbon black 45 sampai dengan $55 \mathrm{phr}$, nilai tegangan putus tidak menunjukkan perbedaan yang nyata, demikian juga penambahan karet alam antara 10 sampai dengan 20 phr tidak menunjukkan perbedaan nyata. Namun untuk variasi kombinasi perbandingan karet nitril / karet alam dengan carbon black menunjukkan perbedaan yang nyata. Hal ini disebabkan interaksi karet dengan carbon black memperkuat terjadinya penambahan nilai tegangan 
putus dibandingkan dengan pengaruh masing-masing variasi.

Menurut Hofman 1989 penambahan carbon black pada karet nitril bisa menambah tegangan putus sampai dengan $25 \mathrm{MPa}$ pada kekerasan $70 \sim 80$ shore A. Pada penelitian yang dilakukan tegangan putus terbaik adalah pada kompon dengan karet nitril 80 bagian, karet alam 10 bagian, dan carbon black 50 bagian dengan nilai tegangan putus $14,32 \mathrm{~N} /$ $\mathrm{mm}^{2}$.

Untuk uji perpanjangan putus ternyata bahwa variasi karet nitril / karet alam , carbon black maupun interaksinya menunjukkan perbedaan yang nyata. Variasi karet nitril / karet alam 70/20 menghasilkan perpanjangan putus tertinggi, namun nilai tegangan putusnya terendah. Hal ini sesuai dengan pendapat Hofman (1989) yang menyebutkan bahwa vulkanisat dari nitril rubber elastisitasnya sangat tergaritung dari grade dari karet nitril tersebut, namun secara umum elastisitas karet nitril lebih rendah bila dibandingkan dengan karet alam, sehingga makin banyak karet alam ditambahkan perpanjangan putusnya makin tinggi. Elastisitas kompon karet nitril bisa relatif tinggi jika dipergunakan karet nitril yang mempunyai kandungan akrilonitril yang rendah.

Sedangkan untuk variasi carbon black, makin banyak jumlah carbon black yang ditambahkan, nilai perpanjangan putus makin turun. Hal ini disebabkan sifat filler yang cenderung menaikkan kekerasan karet, namun sejalan dengan hal tersebut elastisitasnya akan turun. Nilai perpanjangan putus tertinggi adalah kompon dengan karet nitril 70 bagian, karet alam 20 bagian dan carbon black 45 bagian, dengan nilai perpanjangan putus $700 \%$.

\section{Pampat tetap}

Didalam penggunaannya oil seal sangat sering terkena panas dan pampatan sehingga makin kecil nilai pampai tetapnya makin baik karena oil seal tersebut bisa cepat kembali kebentuk semula. Pengujian pampat tetap yang dimaksud adalah nilai constant deflection compression set. Dari hasil uji yang didapatkan ternyata kompon karet mempunyai pampat tetap yang cukup tinggi (ketahanan pampat rendah). Perhitungan statistik dari data hasil uji pampat tetap menunjukkan bahwa baik variasi karet nitril / karet alam, variasi carbon black maupun interaksi karet dengan carbon black menunjukkan beda nyata pada $\mathrm{p} \leq 0,05$. Makin tinggi jumlah karet alam cenderung menurunkan pampat tetap. Hal ini disebabkan karena karet alam mempunyai elastisitas dan daya lenting yang lebih baik dibanding karet nitril, sehingga apabila dipampat lebih mudah kembali ke bentuk semula. Dari 9 formulasi yang diteliti hanya 3 formula yang mempunyai pampat tetap memenuhi persyaratan yaitu formula D.2 (45,14\%); D.7 (45,62\%); dan D.8 (43,16\%); jika dibanding dengan persyaratan JIS B.2402-76, yang mempersyaratkan pampat tetap maksimal 50\%.

Hofman (1989) juga menyebutkan bahwa untuk mendapatkan nilai pampat tetap yang rendah bisa dilakukan dengan membuat kondisi vulkanisasi yang optimum dengan penggunaan carbon black N.550 atau N.770, akselerator TMT/TMTD dan penggunaan sulfur $\pm 1 \mathrm{phr}$. Bahan pemvulkanisasi dari jenis peroksid juga bisa menurunkan nilai pampat tetap, namun bahan ini tidak dipergunakan karena bisa merusak lapisan two roll mill yang dipakai untuk komponding. 


\section{Ketahanan terhadap minyak pelumas}

Ketahanan terhadap minyak pelumas, dilakukan dengan merendam vulkanisat dalam oli SAE 50W kemudian dipanaskan dalam oven pada suhu $100^{\circ} \mathrm{C}$ selama 72 jam. Parameter yang diteliti adalah perubahan kekerasan, tegangan putus, perpanjangan putus dan perubahan volume.

\section{a. Perubahan kekerasan}

Perubahan kekerasan karena perendaman dalam oli SAE 50W sangat dipengaruhi oleh perbandingan jumlah karet nitril / karet alam, jumlah carbon black dan interaksinya. Pada variasi carbon black makin banyak carbon black yang ditambahkan perubahan kekerasan makin kecil. Hal ini kemungkinan disebabkan karena jumlah carbon black yang lebih banyak akan lebih menghambat proses pengusangan vulkanisat sehingga penurunan kekerasannya kecil. Perubahan tex $x$ gil adalah pada kompon dengan karet nitril / karet alam 70/20, carbon black $50 \mathrm{phr}$ dengan nilai rata-rata 2,91\%. Data hasil penelitian jika dibandingkan dengan JIS. B.2402-76 untuk perubahan kekerasan (-5 $\mathrm{s} / \mathrm{d}+10 \%)$ ternyata kompon dengan kode D.1 dan D.5 tidak memenuhi persyaratan.

b. Perubahan tegangan putus dan perpanjangan putus

Berdasarkan hasil perhitungan statistik untuk prosentase perubahan tegangan putus sebelum dan sesudah perendaman ternyata bahwa baik variasi karet nitril / karet alam, variasi carbon black maupun interaksi keduanya menunjukkan perbedaan yang nyata pada $\mathrm{p} \leq 0,05$. Pada variasi karet nitril / karet alam $75 / 15$ untuk semua variasi carbon black, menunjukkan perubahan tegangan putus yang terkecil, dan pada variasi carbon black perubahan tegangan putus terkecil ada pada jumlah carbon black $50 \mathrm{phr}$, sedangkan variasi kombinasi yang menunjukkan perubahan tegangan putus terkecil adalah pada karet nitril / karet alam 75/15 dengan carbon black 55 phr.

Data-data perubahan perpanjangan putus untuk variasi karet nitril / karet alam jika dihitung secara statistik ternyata tidak ada perbedaan yang nyata, namun untuk variasi carbon black ada beda nyata. Pada penggunaan carbon black yang terbanyak ( 55 $\mathrm{phr}$ ), ternyata justru memberikan perubahan perpanjangan putus yang terkecil. Hal ini kemungkinan disebabkan karena carbon black yang lebih banyak terdapat dalam vulkanisat dapat lebih menghambat pengaruh panas pada vulkanisat. Dari 9 formulasi yang diteliti perubahan perpanjangan putus yang tidak memenuhi persyaratan JIS. B. $2402-76(-40 \%)$ adalah formula D.1 dan D.3.

Vulkanisat karet nitril menurut Hofman (1989) mempunyai ketahanan terhadap pengusangan yang lebih baik dibandingkan dengan karet alam maupun SBR. Selian itu vulkanisat karet nitril masih bisa dipergunakan sesudah pengusangan 6 minggu pada temperatur $120^{\circ} \mathrm{C}$, dan lebih tahan lagi pada pengusangan dengan perendaman dalam oli. Ketahanan pengusangan vulkanisat bisa lebih baik jika dipergunakan akselerator yang mengandung cadmium atau cadmium oksid (Hofman 1989), namun hal ini tidak dilakukan mengingat bahan tersebut sangat beracun. Dari 9 formulasi yang diteliti, perubahan tegangan putus yang tidak memenuhi persyaratan JIS. B.2402$76(-20 \%)$ adalah D.1 dan D.9.

c. Perubahan volume

Perubahan volume vulkanisat merupakan perubahan volume sesudah direndam dalam oli SAE 50W selama 72 jam pada suhu $100^{\circ} \mathrm{C}$. Data hasil perhitungan statistik menunjukkan bahwa ada beda nyata antar variasi karet nitril / karet alam, carbon 
black maupun variasi kombinasinya pada $p \leq 0,05$. Kompon dengan variasi karet nitril / karet alam $75 / 15$ dan carbon black $50 \mathrm{phr}$ mempunyai nilai perubahan volume yang cukup kecil yaitu 1,35\%. Hal ini disebabkan karena vulkanisat dari karet nitril merupakan karet yang polar sehingga mempunyai ketahanan terhadap pengembangan (swelling) yang bagus jika direndam dalam bahan yang non polar atau sedikit polar seperti gasolin, minyak mineral, minyak hewan maupun minyak tumbuhan. Ketahanan terhadap perubahan volume ini juga diperkuat oleh grade karet nitril, macam bahan pembantu, jumlah filler, jenis dan jumlah plasticizer serta derajad vulkanisasi. Pada JIS B.2402-76 perubahan volume karena perendaman dalam oli SAE 50W dipersyaratkan -10 sampai $+5 \%$, sehingga formula dengan kode D.1 dan D. 9 tidak memenuhi persyaratan.

\section{KESIMPULAN}

1. Formulasi oil seal terbaik adalah kompon dengan formulasi sebagai berikut : karet nitril $70 \mathrm{phr}$, karet alam $20 \mathrm{phr}$, karet SBR $10 \mathrm{phr}$, carbon black $55 \mathrm{phr}$, DOP $15 \mathrm{phr}$, coumaron resin $5 \mathrm{phr}$, asam stearat $1 \mathrm{phr}$, ZnO $5 \mathrm{phr}$, vulkanox HS $2 \mathrm{phr}$, paraffin wax $0,8 \mathrm{phr}$, minyak aromatik $6 \mathrm{phr}$, CBS 1,2 phr, TMT 0,1 phr Neoblend $2 \mathrm{phr}$ dan sulfur 1,5 phr.

2. Sifat fisis formulasi kompon terbaik adalah : kekerasan 61,7 shore A, tegangan putus $12,01 \mathrm{~N} / \mathrm{mm}^{2}$, perpanjangan putus $383,8 \%$, pampat tetap $45,62 \%$, perubahan setelah perendaman dalam oli SAE $50 \mathrm{~W}, 100^{\circ} \mathrm{C}, 72 \mathrm{jam}$ : perubahan kekerasan 4,32\%; perubahan tegangan putus $16,35 \%$; perubahan perpanjangan putus $17,13 \%$; dan perubahan volume $1,38 \%$.

3. Dari 9 variasi yang diteliti, yang memenuhi persyaratan JIS. B.2402-76 adalah 3 variasi kompon yaitu karet nitril / karet alam 75/15 dengan carbon black $45 \mathrm{phr}$, karet nitril / karet alam 70/20 dengan carbon black $55 \mathrm{phr}$, dan karet nitril / karet alam 75/15 dengan carbon black $55 \mathrm{phr}$.

\section{DAFTAR PUSTAKA}

Anonymous, 1996. Pelumas Produksi Pertamina. Pertamina Indonesia.

Brydson J.A, 1982. Elastomer. Butterworth Scientific. London, Boston, Duban, Singapore, Sydney, Toronto, Welington.

Hofman, 1989. Rubber Technology Handbook. Hanser Publiser, Munich, Vienna, New York.

JIS B. 2402-76. Oil Seal. Japanese Standard Association.

JIS K. 6301-75. Physical Testing Metods for Vulcanized Rubber. Japanese Standard Association.

Morton, Maurice, 1987. Introduction to Rubber Technology. Reinhold Publishing Corporation, New York 